Santa Clara University

Scholar Commons

Psychology

College of Arts \& Sciences

$12-2015$

\title{
Physical aggression, compromised social support, and 10-year marital outcomes: Testing a relational spillover model
}

\author{
Kieran T. Sullivan \\ Santa Clara University, ksullivan@scu.edu \\ Lauri A. Pasch \\ Erika E. Lawrence \\ Thomas N. Bradbury
}

Follow this and additional works at: http://scholarcommons.scu.edu/psych

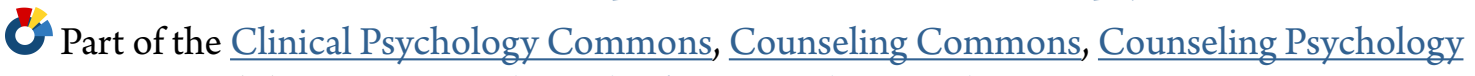
Commons, and the Marriage and Family Therapy and Counseling Commons

\section{Recommended Citation}

Sullivan, K.T., Pasch, Lauri A., Lawrence, E.E., \& Bradbury, T.N. (2015). Physical aggression, compromised social support, and 10-year marital outcomes: Testing a relational spillover model. Journal of Family Psychology, 29, 931-937.

Copyright $(\odot 2015$ American Psychological Association. Posted with permission. This article may not exactly replicate the final version published in the APA journal. It is not the copy of record. http://dx.doi.org/10.1037/fam0000125

This Article is brought to you for free and open access by the College of Arts \& Sciences at Scholar Commons. It has been accepted for inclusion in Psychology by an authorized administrator of Scholar Commons. For more information, please contact rscroggin@scu.edu. 
Physical Aggression, Compromised Social Support, and 10-year Marital Outcomes:

Testing a Relational Spillover Model

Kieran T. Sullivan

Santa Clara University

Lauri A. Pasch

University of California, San Francisco

Erika Lawrence

University of Iowa

Thomas N. Bradbury

University of California, Los Angeles

Author Note

Kieran T. Sullivan, Department of Psychology, Santa Clara University; Lauri A. Pasch, Department of Psychiatry, University of California, San Francisco; Erika Lawrence, Department of Psychology, University of Iowa; Thomas N. Bradbury, University of California, Los Angeles.

Erika Lawrence is now at the Department of Psychology, University of Arizona.

This research was supported by National Institution of Mental Health National Research Service Award F31 MH10779 to Kieran T. Sullivan and by National Institutes of Mental Health Grant MH48674 to Thomas N. Bradbury. We thank Catherine L. Cohan, Joanne Davila, Kathleen Eldridge, Matthew Johnson, Benjamin R. Karney, Gregory Miller, and Ron Rogge, who assisted with data collection and coding.

Correspondence concerning this article should be addressed to Kieran Sullivan, Department of Psychology, Santa Clara University, Santa Clara, CA 95053. 


\begin{abstract}
The purpose of the present study was to test a relational spillover model of physical aggression whereby physical aggression affects marital outcomes due to its effects on how spouses ask for and provide support to one another. Newlywed couples $(n=172)$ reported levels of physical aggression over the past year and engaged in interactions designed to elicit social support; marital adjustment and stability were assessed periodically over the first ten years of marriage. Multilevel modelling revealed that negative support behavior mediated the relationship between physical aggression and 10-year marital adjustment levels whereas positive support behavior mediated the relationship between physical aggression and divorce status. These findings emphasize the need to look beyond conflict when explaining how aggression affects relationships and when working with couples with a history of physical aggression who are seeking to improve their relationships.
\end{abstract}

Keywords: marriage, physical aggression, social support 


\section{Physical Aggression, Compromised Social Support, and 10-Year Marital Outcomes: \\ Testing a Relational Spillover Model}

Intimate partner violence has adverse consequences for relationship satisfaction and stability (Stith, Green, Smith, \& Ward, 2008), and efforts to explain this association typically implicate couples' mismanagement of relationship conflict (e.g., Shortt, Capaldi, Kim, \& Laurent, 2010). Although this work has clarified the broad spectrum of negative behaviors that aggressive couples display during their disagreements, it fails to address how physically and psychologically aggressive acts in general contribute to relationship deterioration. As aggressive couples experience declines in relationship satisfaction even after physical aggression has largely subsided (Lawrence \& Bradbury, 2007), there is reason to suspect aggression compromises a broader range of couple interactions that are critical to healthy relationship maintenance.

In order to shed light on the mechanisms through which physical aggression may affect marital outcomes, we propose a relational spillover model of aggression whereby physical aggression is expected to exert its influence on the developmental course of relationships through its influence on multiple facets of couple functioning, and particularly on those interactional domains that promote feelings of validation and expressions of caring and concern. Expanding research on relational aggression to relatively understudied interactional domains may prove informative in light of growing evidence that relationship functioning is linked with how partners respond to one another's expressions of personal stress and vulnerability (e.g., Cutrona, 1996; Sullivan \& Davila, 2010). In fact, recent findings indicate that the ways in which partners support one another may be uniquely important for understanding why some marriages succeed and some fail (Lawrence et al., 2008; Sullivan, Pasch, Johnson \& Bradbury, 2010).

We know of no published research examining support as a mediator of the link between physical aggression and marital adjustment, though there is a wealth of evidence demonstrating the 
effects of couple support transactions on marital outcomes (Sullivan \& Davila, 2010). However, greater negative affect, animosity toward one another, and ongoing tension seem likely to have consequences for subsequent support transactions. When couples experience uniquely serious conflict such as aggression, spouses may feel less comfortable turning to one another for help, be less willing to provide support, and may view support efforts more negatively. In contrast, individuals who are effective at resolving disagreements and communicating their distinct points of view might also be better at communicating their support needs to each other, thus influencing the quality of their support transactions. Alternatively, aggression may influence support transactions through its effect on emotional intimacy. Partners in healthy relationships are expected to be comfortable being emotionally vulnerable with each other, particularly when they feel overwhelmed and distressed (i.e., emotional intimacy; e.g., Collins \& Feeney, 2010). We would not expect partners in aggressive relationships to feel as if their relationships function as emotionally safe environments, and low intimacy has been shown to predict poor quality support transactions (Brock \& Lawrence, 2014). This study tests a key premise of the relational spillover model by examining whether the association between physical aggression and marital outcomes is mediated by the behaviors partners display when seeking and providing social support. To do so, we assessed relational aggression, relationship satisfaction, and the solicitation and provision of social support among 172 newlywed couples, and subsequently tracked relationship satisfaction and dissolution over the following ten years. ${ }^{1}$ Subsumed by this larger premise are three specific questions that, if clarified, would shed additional light on how aggression comes to affect relationships. First, does aggression operate primarily as a within-person (actor) effect or as a between-person (partner) effect? That is, does aggression affect marital outcomes by leading

\footnotetext{
${ }^{1}$ Findings regarding social support and 10-year marital outcomes as well as physical aggression and 4-year marital outcomes using this sample have been presented elsewhere (author reference)
} 
aggressors to act in invalidating and unsupportive ways or by leading their partners to act in invalidating and unsupportive ways? Second, does aggression operate on the provision or solicitation of support? Variability here would suggest different mechanisms through which aggression influences couple interactions. And third, does aggression operate primarily on negative support behaviors or on positive support behaviors? Aggression effects may be routed through negative behaviors, suggesting broader deficits in the regulation of negative emotion, or through diminished positivity, which would suggest alternate pathways.

\section{Method}

\section{Participants and Procedures}

Newly married couples $(N=172)$ were recruited via marriage licenses to participate in a study of newlywed marriage (see [Author Reference] for detailed descriptions of recruitment and eligibility). Of the 344 spouses participating, trajectories could not be estimated for 8 (4 couples) because they dissolved their marriages before the third assessment and thus had fewer than three data points. Two couples had data missing from one spouse so that trajectories could be estimated only for one partner. Over the 10 years of the study, 33 couples $(19 \%)$ divorced. Of the 344 spouses, $334(97 \%)$ provided sufficient data for the current study. Data from intact couples and from divorced couples prior to dissolution were analyzed.

Husbands and wives averaged $27.6(S D=3.9)$ and $26(S D=3.4)$ years of age, and $15.6(S D$ $=2.2)$ and $16.2(S D=2.0)$ years of education, respectively. Husbands' median annual income ranged from $\$ 21,000$ to $\$ 30,000$; wives ranged from $\$ 11,000$ to $\$ 20,000$. Race and ethnic background for husbands and wives respectively was Caucasian (67\% and 61\%), Asian AmericanPacific Islander (13\% and 15\%), Latino-Chicano (15\% and 16\%), African-American (4\% and 5\%), and Middle Eastern (1\% and 2\%). These data are consistent with the racial and ethnic breakdown of Los Angeles County as reported by the 1990 Census. 
Institutional Review Board approval was obtained prior to commencing data collection. At Time 1 spouses independently completed questionnaires including a consent form, demographic forms, and measures of marital adjustment and physical aggression prior to and during a 3-hour laboratory session. During the laboratory session, couples also participated in two videotaped discussions of individual problems. Spouses completed eight additional marital adjustment questionnaires by mail and in a second laboratory session, thus providing adjustment data every 6 months over the first 4 years of marriage and again approximately 9 and 10 years after their weddings. For all questionnaires completed via mail, spouses were instructed in a telephone call and in a cover letter to complete the questionnaires independently. Couples were paid $\$ 25$ for questionnaires completed via mail and $\$ 75$ for each laboratory session.

\section{Measures}

Marital Adjustment Test (MAT; Locke \& Wallace, 1959). Marital adjustment was assessed using the MAT, a widely used measure with a test-retest reliability of .75 over a 3-week interval (MacEwen \& Barling, 1988) and a split-half reliability of .90 (Locke \& Wallace, 1959). Scores range from 2 to 158, with higher scores indicating greater marital adjustment.

Conflict Tactics Scales (CTS; Straus, 1979). Physical aggression was assessed using the CTS, an 18-item self-report measure of conflict tactics. The factor structure and validity of the CTS are well-established (e.g., Barling, O’Leary, Jouriles, Vivian, \& MacEwen, 1987; Straus \& Mickey, 2012). For this study, the eight items assessing physically aggressive tactics (ranging from throwing something at partner to using a knife or a gun on partner) were used for quantifying physical aggression. Spouses indicated whether they or their partner had engaged in any of the 8 types of physically aggressive acts in the year prior to the first assessment. Frequency scores were summed across the physical aggression items to obtain sum scores. At the onset of marriage, $29 \%$ of couples ( $16 \%$ of husbands and $24 \%$ of wives) were identified as having engaged in physical 
aggression in the last year based on their own and/or their partner's report ${ }^{2}$.

Support discussions. Support discussions were structured to create opportunities for spouses to solicit and offer support for making a personal change. A spouse was randomly selected to adopt the role of support solicitor (or "helpee") and was asked to "talk about something you would like to change about yourself." When identifying a topic, spouses were encouraged to identify an important personal characteristic, problem, or issue that was not a source of tension in the marriage. The partner was assigned the role of support provider (or "helper") and was instructed to "be involved in the discussion and respond whatever way you wished." For the second discussion the roles were reversed. Spouses had little difficulty identifying topics, and common topics included losing weight, making a career change, and improving family relationships.

Social Support Interaction Coding System (SSICS; Pasch, Harris, Sullivan, \& Bradbury, 2004). Spouses' behaviors were coded using the SSICS. Trained graduate and undergraduate coders assigned a code for each speaking turn for the spouse who had chosen the topic (the helpee) and the spouse who was responding (the helper). Behavior was rated as either positive or negative and helper's positive behavior was further delineated as positive instrumental, positive emotional, or positive other. A summary positive helper code was created to simplify analyses by summing the three positive codes. Intra-class correlations indicate adequate inter-observer reliability (.80 and .86 for helpers' negative and positive affect; .75 and .79 for helpees' negative and positive affect). Multiple studies have established the concurrent, convergent and discriminative validity of the SSICS (for a summary see Pasch, Harris, Sullivan, \& Bradbury, 2004).

\section{Data Analyses}

All analyses were conducted using hierarchical linear modeling software (HLM 6.02;

\footnotetext{
${ }^{2}$ When items assessing verbal aggression are included, $76 \%$ of husbands and $79 \%$ of wives had engaged in aggression in the past year. Although the focus of this paper is on physical aggression, we note that analyses based on verbal and physical aggression combined yield the same pattern of results.
} 
Raudenbush, Bryk, Cheong, Congdon, \& Toit, 2004). Growth curve modeling techniques (GCM; Bryk \& Raudenbush, 1992) were used to estimate marital trajectories. Time was measured in days since the couple's wedding and divided by 30 (to be analogous to a month) and group-mean centered to represent the midpoint of the assessments for each spouse. Continuous variables marital adjustment -- were group mean centered at Level 1 . This baseline model is a within-subject regression of each spouse's adjustment scores onto a line with a constant, a slope, and an error coefficient. Intercepts represent the mean score on a given variable across time. Time 1 physical aggression and support behaviors were entered at Level 2 .

Actor-partner interdependence modeling (APIM) techniques for mixed independent variables (Kenny, Kashy, \& Cook, 2006) were also used in the present study. The possibility of interdependence between husbands' and wives' data was incorporated into our analyses in four ways. First, when dyad members are distinguishable, as in our sample of heterosexual married couples, there are potentially two actor effects and two partner effects; all four paths were included in analyses. Second, correlations between husbands' and wives' predictors were estimated in all equations. Third, the residual non-independence in outcome scores is represented by the correlation between the error terms in husbands' and wives' outcomes, and was estimated in all equations. Fourth, we ran chi-square tests to assess the homogeneity of husbands' versus wives' Level 1 variance for each baseline model. When this test was significant, those residual terms were entered as simultaneous outcomes of all relevant predictors in subsequent models.

\section{Results}

\section{Descriptive Statistics}

At Time 1, for husbands and wives respectively, mean marital adjustment scores were $126.9(S D=17.1)$ and $130.3(S D=16.2)$ and mean scores on the physical aggression items of the CTS were $6.08(S D=5.9)$ and $6.94(S D=7.8)$. Regarding support provision, for husbands and 
wives, spouses engaged in positive behavior an average of $60 \%(S D=23 \%)$ and $63 \%(S D=22 \%)$ of the time and they both engaged in negative behavior $7 \%$ (SDs $=13 \%$ and $14 \%$, respectively) of the time. Regarding support solicitation, for husbands and wives, spouses engaged in positive behavior an average of $66 \%(S D=22 \%)$ and $64 \%(S D=22 \%)$ of the time and in negative behavior $4 \%(S D=10 \%)$ and $7 \%(S D=13 \%)$ of the time. See (author reference) for further details on the physical aggression variables and (author reference) for further details on support variables as well as baseline marital trajectories. Within- and between-spouse correlations for all variables are reported in Table 1. As expected, physical aggression and marital adjustment were negatively correlated and marital adjustment was positively correlated with positive support behavior and negatively correlated with negative support behavior, within and between spouses. Physical aggression was negatively associated with positive support behaviors and positively associated with negative support behaviors in almost all cases.

\section{Mediation Analyses}

We used the Baron and Kenny (1986) method to examine whether support mediated the relationship between physical aggression and levels of marital adjustment over the first 10 years of marriage. First, linear regression was used to test whether physical aggression in the past year predicted support behavior, controlling for Time 1 marital adjustment. As expected, physical aggression was negatively associated with positive support behavior and positively associated with negative support behavior $(p<.01$ except when indicated below). For husbands and wives, physical aggression was related to husbands' negative helpee behavior $(\beta=.30$ and .24$)$ and wives' negative helpee behavior $(\beta=.30$ and .30$)$ as well as husbands' negative helper behavior $(\beta=.26$ and .26) and wives' negative helper behavior $(\beta=.24$ and .28). Physical aggression was also significantly associated with husbands' positive helpee behavior $(\beta=-.22$ and -.22$)$ and wives' positive helpee behavior $(\beta=-16$ and $-.16, p<.05)$. The relationships between aggression and 
positive helper behavior were only significant for wives' aggression $(\beta=-.27$ and -.27$)$.

Next, HLM analyses were used to test whether physical aggression was associated with mean levels of marital adjustment over time (see Table 2). Husbands' and wives' physical aggression significantly predicted adjustment levels in the expected direction across spouse and across topic. Husbands' and wives' physical aggression were associated with adjustment levels within $(r=.22, p<.01$ and $r=.29, p<.01)$ and between $(r=.26, p<.01$ and $r=.17, p<.05)$ spouses. Physical aggression was not associated with change in marital adjustment over time.

As reported in (author reference) husbands' and wives' support behaviors significantly predicted adjustment levels in the expected direction across spouse and across topic, without exception. That is, positive support predicted higher marital adjustment and negative support predicted negative marital adjustment for husbands and wives in helpee and helper roles.

Finally, HLM analyses were used to test whether the effect sizes for the direct effects of physical aggression on marital adjustment levels decreased after controlling for support behavior (see Table 2). Effect sizes decreased for all 32 tests of mediation. We used Sobel tests (Sobel, 1982) to test the significance of the indirect effects of physical aggression on marital adjustment levels via support (significant indirect effects are noted in bold on Table 2). Tests of indirect effects were significant for 15 of the 16 paths involving negative support behavior; in contrast none of 16 paths involving positive support behavior were significant. This suggests that the association between physical aggression and levels of marital adjustment was mediated at least partially by negative support behavior.

Full mediation. The effect of aggression on husbands' level of adjustment became nonsignificant after controlling for support behavior in 9 of the 16 analyses, indicating full mediation (Baron and Kenny, 1986). Most notably, the effect of wives' aggression on husbands' marital adjustment levels is fully mediated by husbands' and wives' negative support-seeking behavior and 
negative support provision, although it should be noted the direct effect of wives' aggression was at the threshold of significance. In addition, the effect of husbands' physical aggression on husbands' adjustment level is fully mediated by husbands' negative support-seeking behavior.

Support solicitation and support provision. Regarding support solicitation, all the indirect effects of physical aggression on marital adjustment levels via negative support solicitation were significant, within and between partners, with only one exception (i.e., the indirect effect of wives' aggression on husbands' adjustment levels via wives' negative solicitation; see Table 2). Regarding support provision, all of the indirect effects of aggression on adjustment levels via negative support provision were significant, within and between partners, without exception. Thus it appears that husbands' and wives' negative behavior when soliciting and providing support is almost always important in understanding the relationship between physical aggression and marital adjustment levels.

\section{Mediational Analyses Predicting Marital Dissolution}

Hierarchical logistic regression analyses were used to test whether physical aggression and support behavior were associated with marital status at Time 10, after controlling for Time 1 marital adjustment. Physical aggression significantly predicted marital status at Time 10 for husbands, $\chi_{\text {step }}^{2}=7.1, p<.01$, Negelkerke $R^{2}=.06$ and for wives, $\chi_{\text {step }}^{2} 6.3, p<.05$, Negelkerke $R^{2}=.06$, indicating that physical aggression accounted for about $6 \%$ of the variance in marital status over the first 10 years of marriage. Positive support behavior significantly predicted marital status at Time $10, \chi_{\text {block }}^{2}=11.7, p<.01$ and Negelkerke $R^{2}=.11$ for husbands and $\chi^{2}$ block $=12.2, p<$ .01 and Negelkerke $R^{2}=.11$ for wives, indicating that positive support behavior at Time 1 accounted for about $11 \%$ of the variance in marital status 10 years later. Regarding support solicitation and provision, for husbands, support solicitation behavior significantly predicted marital status $(B=-3.1, p<.001)$ but support provision behavior did not $(B=1.0, p=.28)$. For 
wives, the opposite pattern was true; positive support provision behavior significantly predicted marital status $(B=-2.1, p<.05)$ but positive support solicitation behavior did $\operatorname{not}(B=-1.4, p=$ .13). Negative support behavior was not associated with marital status.

Mediation was tested with a final set of hierarchical logistic regression equations wherein Time 1 marital adjustment was entered in the first block, the positive support behaviors were entered in the second block, and aggression was entered in the third block. Within spouse, for husbands, the association between physical aggression and marital status was reduced from $\chi^{2}$ block $=$ $11.8, p<.05$ to $\chi_{\text {block }}^{2}=4.5, p<.05$ after controlling for support behavior. For wives, the association between physical aggression and marital status became non-significant after controlling for support behavior, $\chi^{2}$ block $=2.4, p=.12$. Between spouse, the association between wives' physical aggression and marital status was reduced to $\chi^{2}$ block $=3.9, p<.05$ after controlling for husbands' support behavior. The association between husbands' physical aggression and marital status became non-significant after controlling for wives' support behavior, $\chi^{2}{ }_{\text {block }}=2.8, p=.10$. These findings indicate that the effect of aggression on marital status is fully mediated by wives' positive support behavior and partially mediated by husbands' positive support behavior.

Support solicitation and support provision. Sobel tests indicated that the indirect effects of husbands' $(z=2.26 ; p<.05)$ and wives' $(z=2.19 ; p<.05)$ physical aggression on marital dissolution via husbands' positive support solicitation were significant, but indirect effects via wives' positive support solicitation were not significant. Conversely, the indirect effects of husbands' $(z=2.47 ; p<.05)$ and wives' $(z=2.46 ; p<.05)$ physical aggression on marital dissolution via wives' positive support provision were significant, but indirect effects via husbands' positive support provision were not significant. These findings indicate that wives' and husbands' aggression affects husbands' support solicitation and wives' support provision, which in turn affects their marital status. 


\section{Discussion}

Although relationships marked by higher levels of physical aggression are at elevated risk for distress and dissolution, most prior attempts to explain this association have turned to conflict management and problem-solving as likely mediators. We argued instead, consistent with a relational spillover model that aggression detracts from domains of couple interaction that are critical to long-term relationship maintenance. We focused specifically on social support as one such domain likely to be compromised by physical aggression, and examined three specific questions to clarify the interactional pathways by which aggression may decrease satisfaction and increase the likelihood of divorce and separation.

First we examined whether aggression operated upon one's own versus one's partner's social support. Results were clear in indicating that, for husbands and for wives, aggression was associated with their own support behavior and their partners' support behavior. Thus poor support behavior cannot be explained solely by, for example, feelings of guilt on the part of the aggressor (an actor effect) or feelings of fear and resentment on the part of the partner (a partner effect). Instead, to the extent that social support does mediate aggression-to-outcome associations, those social support behaviors appear to be a reflection of the aggressive acts of either or both partners.

Second, we examined whether aggression came to be associated with outcomes because of its effects on support provision or solicitation. Here we observed that the relationship between physical aggression and marital adjustment was mediated by support solicitation and support provision for husbands and wives. However, we observed a gender difference in regards to the relationship between physical aggression and marital stability such that physical aggression led to an increased likelihood of divorce via support solicitation for husbands and via support provision for wives. Thus it seems that behaviors displayed when seeking and providing support are both important for understanding the effects of physical aggression on marital adjustment; when 
predicting divorce, however, it appears that it is the erosion of husbands' abilities to effectively seek support and the erosion of wives' abilities to provide support that appear to be critical for understanding how physical aggression leads to marital instability.

Finally, with our third question we asked whether the association between aggression and marital outcomes was mediated primarily by increased negative behaviors or decreased positive behaviors. Our results indicate that the answer to this question depends on whether relationship satisfaction or stability is the outcome in question: Negative behavior mediated the relationship between aggression and satisfaction but positive behaviors mediated the relationship between aggression and marital stability. Thus it seems that spouse are less satisfied with their relationships to the extent their support behaviors are negative, but it is the relative lack of positive support and validation that increases the risk of divorce. Future studies are needed to examine whether these two results are linked, in that acts of aggression and the negative support behaviors that ensue from these acts might lead partners to be less positive in their support transactions, perhaps increasing risk for dissolution.

Interpretation of the present findings is limited in several important respects. First, although we did collect longitudinal data, this study is nevertheless correlational and is thus subject to all the limitations of nonexperimental research. Second, the behaviors examined in this study were sampled in a laboratory setting and may not represent couples' typical discussions in natural settings. However, research on this matter (e.g., Foster, Caplan, \& Howe, 1997; Heyman, 2001; Owen et al., 2006) indicates that lab interactions are fairly representative. Third, the participants were recruited through marriage licenses; this recruitment strategy tends to yield relatively low-risk samples (as compared with media solicitations; Karney et al., 1995). Nevertheless, the present sample was ethnically diverse, yielded mean CTS scores above 6.0, and 33\% of the sample divorced by Year 10, suggesting this sample was not necessarily at low risk. 
Taken together, these findings emphasize the need to look at support interactions when seeking to explain the effects of aggression on relationships, and when working with couples who have experienced physical aggression and who are seeking to strengthen their relationships. Disenchantment with the quality of support exchanged within a relationship may reflect prior experiences with aggression, even after the aggression has subsided, and careful consideration of a couples' relationship history might provide practitioners with insights into why two partners may be less supportive than expected. Recent findings demonstrate that aggressive newlywed couples decline more rapidly in satisfaction than less aggressive couples following preventive interventions (Williamson et al., in press), and the present study indicates that sensitive attention to difficulties in the provision and receipt of social support among these couples could improve their outcomes. More specifically, practitioners may need to focus on encouraging couples to become aware of and change negative behaviors when asking for and providing support. At the same time, in view of the sex differences found here, enabling men to ask for support and validation in more positive ways and helping women provide support in more positive ways may reduce risk of divorce among atrisk couples. 


\section{References}

Barling, J., O'Leary, K.D., Jouriles, E.N., Vivian, D., \& MacEwen, K.E. (1987). Factor similarity of the conflict tactics scales across samples, spouses, and sites: Issues and implications. Journal of Family Violence, 2, 37-54. doi: 10.1007/BF00976369

Baron, R.M., \& Kenny, D.A. (1986). The moderator-mediator variable distinction in social psychological research: Conceptual, strategic, and statistical considerations. Journal of Personality and Social Psychology, 51, 1173-1182. doi: 10.1037/0022-3514.51.6.1173

Brock, R. L., \& Lawrence, E. (2014). Intrapersonal, interpersonal, and contextual risk factors for overprovision of partner support in marriage. Journal of Family Psychology, 28, 54-64. doi: $10.1037 / \mathrm{a} 0035280$

Bryk, A. S., \& Raudenbush, S. W. (1992). Hierarchical linear models: Application and data analysis methods. Newbury Park, CA: Sage.

Collins, N., \& Feeney, B. (2000). A safe haven: An attachment theory perspective on support seeking and caregiving in intimate relationships. Journal of Personality and Social Psychology, 78, 1053-1073. doi: 10.1037/0022-3514.78.6.1053

Cutrona, C.E. (1996). Social Support in Couples: Marriage as a Resource in Times of Stress. Thousand Oaks, CA: Sage Publications, Inc.

Foster, D.A., Caplan, R.D., Howe, G.W. (1997). Representativeness of observed couple interaction: Couples can tell, and it does make a difference. Psychological Assessment, 9, 285-294. doi: 10.1037/1040-3590.9.3.285

Heyman, R.E. (2001). Observation of couple conflicts: Clinical assessment applications, stubborn truths, and shaky foundations. Psychological Assessment, 13, 5-35. doi: 10.1037/10403590.13.1.5

Karney, B.R., Davila, J., Cohan, C.L., Sullivan, K.T., Johnson, M.D., \& Bradbury, T.N. (1995). An 
empirical investigation of sampling strategies in marital research. Journal of Marriage and the Family, 57, 909-920. doi: 10.2307/353411

Kenny, D.A., Kashy, D.A., \& Cook, W.L. (2006). Dyadic data analysis. New York, NY, US: Guilford Press.

Lawrence, E., \& Bradbury, T.N. (2007). Trajectories of change in physical aggression and marital satisfaction. Journal of Family Psychology, 21, 236-247. doi:10.1037/0893-3200.21.2.236

Lawrence, E., Bunde, M., Barry, R.A., Brock, R.L., Sullivan, K.T., Pasch, L.A., White, G.A., Dowd, C.E., \& Adams, E.E. (2008). Partner support and marital satisfaction: Support amount, adequacy, provision, and solicitation. Personal Relationships, 15, 445-463. doi: 10.1111/j.1475-6811.2008.00209.x

Locke, H. J., \& Wallace, K. M. (1959). Short marital adjustment predictions test: Their reliability and validity. Marriage and Family Living, 21, 251-255. doi: 10.2307/348022

MacEwen, K., \& Barling, J. (1988). Inter-role conflict, family support and marital adjustment of employed mothers: A short-term longitudinal study. Journal of Organizational Behavior, 9, 241-255.

Owen, D.J., Heyman, R.E. Slep, A.M. (2006). The Risk of Partner Aggression Research: Impact of Laboratory Couples Conflict Protocols on Participants. Violence and Victims, 21, 483-497. doi: 10.1891/vivi.21.4.483

Pasch, L. A., Harris, K. M., Sullivan, K. T., \& Bradbury, T. N. (2004). The social support interaction coding system. In P. Kerig and D. Baucom (Eds.) Couple observational coding systems. Mahwah, N.J.: Lawrence Erlbaum.

Raudenbush, S., Bryk, A., Cheong, Y.F., Congdon, R., \& Toit, M. (2004). HLM 6: Hierarchical linear and nonlinear modeling. Lincoln, I.L.: Scientific Software International.

Shortt, J.W., Capaldi, D.M., Kim, H.K., \& Laurent, H.K. (2010). The effects of intimate partner 
violence on relationship satisfaction over time for young at-risk couples: The moderating role of observed negative and positive affect. Partner Abuse, 1, $131-151$. doi:

$10.1891 / 1946-6560.1 .2 .131$

Sobel, M. E. (1982). Asymptotic intervals for indirect effects in structural equations models. In S. Leinhart (Ed.), Sociological methodology 1982 (pp.290-312). San Francisco: Jossey-Bass.

Stith, S.M., Green, N.M. Smith, D.B., \& Ward, D.B. (2008). Marital satisfaction and marital discord as risk markers for intimate partner violence: A meta-analytic review. Journal of Family Violence, 23, 149-160. doi: 0.1007/s10896-007-9137-4

Straus, M.A. (1979). Measuring intrafamily conflict and violence: The Conflict Tactics (CT) Scales. Journal of Marriage and the Family, 41(1), 75-88. doi: 10.2307/351733.

Straus, M.A. \& Mickey, E.L. (1989). Reliability, validity, and prevalence of partner violence measured by the Conflict Tactics Scales in male-dominant nations. Aggression and Violent Behavior, 17, 463-474. doi: 10.1016/j.avb.2012.06.004

Sullivan, K.T., \& Davila, J. (Eds). (2010). Support processes in intimate relationships. New York: Oxford Press.

Sullivan, K.T., Pasch, L.A., Johnson, M.D., \& Bradbury, T.N. (2010). Social support, problemsolving, and the longitudinal course of newlywed marriage. Journal of Personality and Social Psychology, 98, 631-644. doi: 10.1037/a0017578

Williamson, H.C., Rogge, R.D., Cobb, R.J., Lawrence, E., Johnson, M.D., \& Bradbury, T.N. (in press pending minor revision). Risk moderates the outcome of relationship education: A randomized controlled trial. Journal of Consulting and Clinical Psychology. 83, 617-629. doi: $10.1037 / \mathrm{a} 0038621$ 
Table 1

Within-spouse and Between-spouse Correlations Among Husbands' and Wives' Time 1 Marital Adjustment, Reports of Physical Aggression in the Past Year, and Time 1 Support Behaviors

\begin{tabular}{|c|c|c|c|c|c|}
\hline \multirow{2}{*}{$\begin{array}{l}\text { Marital } \\
\text { Adiustment }\end{array}$} & \multirow{2}{*}{$\begin{array}{l}\text { Physical } \\
\text { Aggression }\end{array}$} & \multicolumn{2}{|c|}{ Helper } & \multicolumn{2}{|c|}{ Helpee } \\
\hline & & Positive & Negative & Positive & Negative \\
\hline
\end{tabular}

Within-spouse Correlations ${ }^{1}$

\begin{tabular}{|c|c|c|c|c|c|c|c|c|}
\hline Marital Adjustment & & $-.21 * *$ & .25 & $* *$ & -.19 & & $.16^{*}$ & $-.26 * *$ \\
\hline Physical Aggression & $-.29 * *$ & & -.18 & $* *$ & .30 & $* *$ & $-.24 * *$ & $.34 * *$ \\
\hline \multicolumn{9}{|l|}{ Helper } \\
\hline Positive & $.15 *$ & $-.31 * *$ & & & -.70 & $* *$ & $.39 * *$ & $-.33 * *$ \\
\hline Negative & $-.15 *$ & $.30 * *$ & -.68 & $* *$ & & & $-.37 * *$ & $.46 * *$ \\
\hline \multicolumn{9}{|l|}{ Helpee } \\
\hline Positive & $.19 * *$ & $-.20 * *$ & .39 & $* *$ & -.33 & $* *$ & & $-.37 * *$ \\
\hline Negative & $-.18 * *$ & $.32 * *$ & -.41 & $* *$ & .52 & $* *$ & $-.70 * *$ & \\
\hline
\end{tabular}

Between-spouse Correlations

Wives

\begin{tabular}{lcccccc} 
Marital Adjustment & $.52 * *$ & $-.25 * *$ & $.23 * *$ & $-.20 * *$ & .11 & -.12 \\
Physical Aggression & $-.19 * *$ & $.57 * *$ & $-.14 *$ & $.30 * *$ & $-.24 * *$ & $.28 * *$ \\
$\begin{array}{l}\text { Helper } \\
\quad \text { Positive }\end{array}$ & .12 & $-.29 * *$ & $.33 * *$ & $-.33 * *$ & $.81 * *$ & $-.53 * *$ \\
$\quad$ Negative & $-.23 * *$ & $.26 * *$ & $-.27 * *$ & $.38 * *$ & $-.55 * *$ & $.77 * *$ \\
$\begin{array}{l}\text { Helpee } \\
\quad \text { Positive }\end{array}$ & $.17 *$ & $-.20 * *$ & $.77 * *$ & $-.57 * *$ & $.38 * *$ & $-.34 * *$ \\
$\quad$ & & & & & & \\
$\quad$ Negative & $-.19 * *$ & $.32 * *$ & $-.53 * *$ & $.72 * *$ & $-.38 * *$ & $.43 * *$ \\
\hline
\end{tabular}

${ }^{1}$ Husbands' correlations appear above the diagonal; wives' correlations appear below the diagonal. $* \mathrm{p}<.05 . * * \mathrm{p}<.01$. 
Table 2

The Effects of Physical Aggression on Marital Adjustment Levels Before and After Controlling for Support

\begin{tabular}{|c|c|c|c|c|}
\hline $\begin{array}{l}\text { Physical } \\
\text { Aggression }\end{array}$ & $\begin{array}{l}\text { Effect of Aggression } \\
\text { on Marital Adjustment }\end{array}$ & $\begin{array}{l}\text { Controlling } \\
\text { for }\end{array}$ & $\begin{array}{l}\text { Effect of Aggression } \\
\text { After Controlling } \\
\text { for Support Behavior }\end{array}$ & $\begin{array}{l}\text { Change in } \\
\text { Effect Sizes }\end{array}$ \\
\hline
\end{tabular}

Husband Satisfaction Level

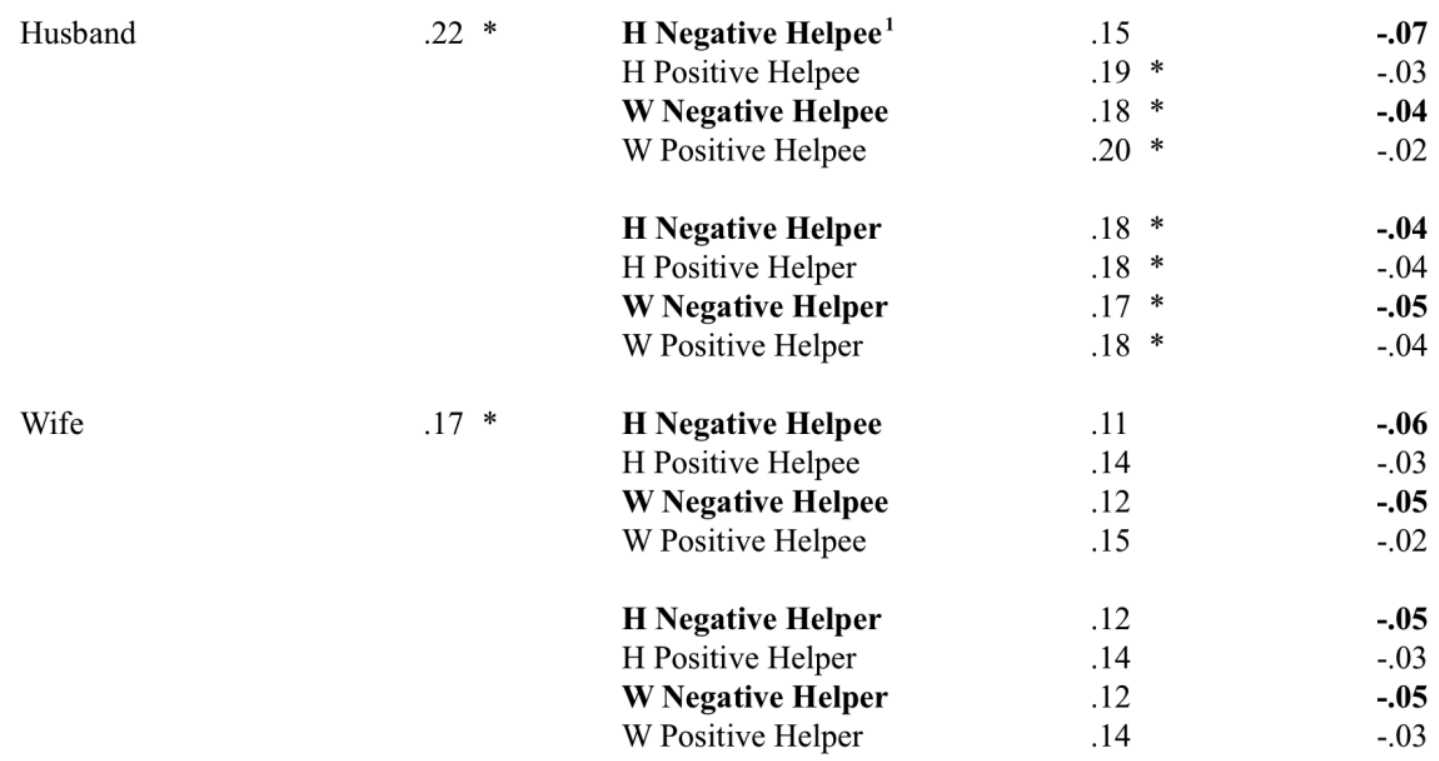

Wife Satisfaction Level

Husband

$.26 * *$

H Negative Helpee

$18 *$

$-.06$

H Positive Helpee

$-.04$

W Negative Helpee

$.22 *$

$-.05$

W Positive Helpee

$.21 *$

$-.03$

H Negative Helper

$.23 * *$

$.21 * \quad-.05$

H Positive Helper

W Negative Helper

$.23 * *$

$-.03$

W Positive Helper

$.18 *$

$-.06$

$.23 * * \quad-.03$

Wife

$.29^{* *}$

H Negative Helpee

$.26 * *$

$-.03$

H Positive Helpee

$-.03$

W Negative Helpee

$.26 * *$

$-.05$

W Positive Helpee

$.24 * *$

$-.02$

H Negative Helper

$.27 *$

$-.04$

H Positive Helper

W Negative Helper

${ }^{1}$ Items in bold represent significant indirect pathways based on Sobel tests

$* \mathrm{p}<.05 . * * \mathrm{p}<.01$ 